\title{
A prospective study on postoperative discomfort after 20-gauge pars plana vitrectomy
}

\author{
This article was published in the following Dove Press journal: \\ Clinical Ophthalmology \\ 24 July 2015 \\ Number of times this article has been viewed
}

\author{
Ji-guo $\mathrm{Yu}^{1, *}$ \\ Fang $\mathrm{Ni}^{1, *}$ \\ Yi Xiang' \\ Yi-fan Feng ${ }^{2}$ \\ Jue Wang' \\ Xun-an Fu' \\ 'Department of Ophthalmology, the \\ Central Hospital of Wuhan, Wuhan, \\ Hubei Province, ${ }^{2}$ Department of \\ Ophthalmology, Zhongshan Hospital, \\ Fudan University, Shanghai, People's \\ Republic of China \\ *These authors contributed equally \\ to this work
}

Correspondence: Xun-an Fu

Department of Ophthalmology, the

Central Hospital of Wuhan, No 26

Shengli Street, Wuhan 4300I4, Hubei

Province, People's Republic of China

Tel +86 2782201749

Fax +862782201745

Email fxayanke@163.com
Purpose: To evaluate postoperative pain and other irritation symptoms after 20-gauge (20G) pars plana vitrectomy.

Materials and methods: A total of 110 consecutive patients were enrolled in our studies, and 87 patients who underwent the conventional 20G pars plana vitrectomy were included in the final analysis. All vitrectomies were performed using the same surgical technique by the same surgeon. Patients were examined before surgery and 1 day, 3 days, 7 days, 1 month, and 2 months postoperatively. The main outcome measures include patient age and sex, intraocular pressure (IOP), ocular pain, pain score, pain medication use, and other irritation symptoms comprising itching, foreign body sensation, burning, photophobia, and dryness. The pain was evaluated using the Numerical Rating Scale scored from 0 to 10.

Results: Postoperative pain was relatively common during the first day after surgery, as it was reported by 43 (49.4\%) patients. Then, the prevalence gradually decreased to eleven $(12.6 \%)$ patients at 2 months. Most patients reported mild or moderate pain, with a pain score of $1-5$, but only four patients were given analgesics for ocular pain. A postoperative rise of IOP was noted in 25 patients at day 1 . Most of these patients with high IOP reported moderate pain. Other ocular irritation symptoms were varied after surgery. There was still one-quarter of patients that had foreign body sensation and dryness symptoms at month 2 after surgery.

Conclusion: Mild and moderate ocular pain were relatively common after $20 \mathrm{G}$ vitrectomy, which is more often associated with elevated IOP. Other irritation symptoms were also presented after surgery and could affect the life quality of patients. Therefore, the discomforts after $20 \mathrm{G}$ pars plana vitrectomy should be of concern, and timely management should be provided as part of routine postoperative care.

Keywords: eye, pain, irritation symptom, 20G vitrectomy

\section{Introduction}

With the development and maturation of vitrectomy in recent years, most incurable retinal diseases in the past, such as retinal detachment, vitreous hemorrhage, and proliferative diabetic retinopathy, obtain an effective treatment. ${ }^{1,2}$ A significant number of cases are conducted by pars plana vitrectomy using the conventional 20-gauge (20G) technique, although the sutureless $23 \mathrm{G}$ and $25 \mathrm{G}$ vitrectomy techniques are being increasingly used. ${ }^{3}$ In the conventional $20 \mathrm{G}$ vitrectomy, three large incisions requiring a $1.20 \mathrm{~mm}$ wide sclerotomy are made using a microvitreoretinal blade through the sclera after conjunctival peritomy. At the end of the procedure, absorbable sutures are used to simultaneously close the scleral and conjunctival wounds. ${ }^{4}$ This may cause discomforts such as postoperative pain, foreign body sensation, itching, and dryness to patients. ${ }^{5}$ Conflicting with previous studies, ${ }^{5,6}$ few patients suffer severe postoperative pain after $20 \mathrm{G}$ vitrectomy in our clinical practices. But other common 
symptoms, such as foreign body sensation, dryness, and so on, are commonly encountered.

To date, there are few studies that focus on these postoperative discomforts, which possibly affect the quality of life for patients. Therefore, in order to provide a reference to the ophthalmologists for the prevention and treatment of any irritation symptoms, we performed a prospective study to evaluate the incidence and severity of pain and other ocular irritation symptoms after $20 \mathrm{G}$ pars plana vitrectomy.

\section{Materials and methods Subjects}

This prospective case series study was approved by the institutional ethics committee and followed the tenets of the Declaration of Helsinki. Patients who underwent primary $20 \mathrm{G}$ pars plana vitrectomy at the Central Hospital of Wuhan (Hubei, People's Republic of China) between January 2013 and December 2013 were enrolled. The procedures were fully explained to each patient, and each provided written informed consent.

Patients with monocular vitreoretinal pathology requiring pars plana vitrectomy performed under local anesthesia were enrolled. Patients with retinal detachment requiring scleral buckling, those who underwent surgery under general anesthesia, or those who had dementia or other diseases that may impair their cognitive function were excluded. In addition, we also excluded those patients who had other diseases including keratitis, scleritis, conjunctivitis, severe cataract, and glaucoma that could affect the assessment of postoperative symptoms.

\section{Surgical technique}

All pars plana vitrectomies in this study were performed using the same surgical technique by the same surgeon (FXA). After retrobulbar anesthesia, the $20 \mathrm{G}$ vitrectomy procedure began with three triangular incisions created using curved scissors in the conjunctiva at 3 o'clock and 9 o'clock. A 20G microvitreoretinal blade, inserted through the conjunctiva at an angle of $10^{\circ}-15^{\circ}$, was used to create a scleral tunnel located $3.5 \mathrm{~mm}$ posterior to the limbus in phakic patients. The infusion cannula was inserted through the inferotemporal tunnel and was fixed with an 8-0 absorbable suture (Ethicon; Johnson \& Johnson, New Brunswick, NJ, USA). The $20 \mathrm{G}$ instruments were inserted into the other two tunnels that were placed at the superior quadrants. After vitrectomy, the sclerotomies and conjunctiva were closed with the $8-0$ absorbable sutures, and dexamethasone $(4.0 \mathrm{mg})$ and gentamicin $(8.0 \mathrm{mg})$ were subconjunctivally injected. After the surgery, patients were given drops of antibiotics like ofloxacin eye ointment (3.5 g;
Sinqi Co., Ltd., Shenyang, People's Republic of China) three times, once daily; recombinant human epidermal growth factor derivative eye drops $(15,000 \mathrm{IU} / 3 \mathrm{~mL}$; Watsin Genetech Co., Ltd., Shenzhen, People's Republic of China) four times, once daily; and corticosteroids like tobramycin and dexamethasone eye drops ( $5 \mathrm{~mL}: 15 \mathrm{mg}: 5 \mathrm{mg}$; Alcon-Couvreur nv, Rijksweg, Belgium) four times, once daily.

\section{Postoperative follow-up}

Patients were examined before surgery and 1 day, 3 days, 7 days, 1 month, and 2 months postoperatively.

\section{Main outcome measures}

The data were collected using a structured study form and a questionnaire. The following data were collected and analyzed: patient age and sex; indications for surgery; type of intravitreal tamponade (gas, silicone oil); operative time; intraocular pressure (IOP) ocular pain; the pain medication used; and other irritation symptoms including itching, foreign body sensation, burning, photophobia, and dryness. Pain was evaluated using the Numerical Rating Scale (NRS) with scores from 0 to 10 , where $0=$ no pain, $1-3=$ mild pain, $4-6=$ moderate pain, and $7-10=$ severe pain. ${ }^{7,8}$ Patients were instructed and asked to select a single number that best represents the level of pain intensity that they are experiencing. Patients were asked whether analgesics like diclofenac sodium were needed to relieve ophthalmic pain. In addition, some yes/no and open-ended questions were used to ask patients to evaluate the presence and severity of the other ocular irritation symptoms mentioned earlier.

\section{Statistical analysis}

All data were recorded on Microsoft Excel spreadsheets. Continuous variables were expressed as the mean \pm standard deviation (SD) if meeting the normal distribution, or using the median. The Wilcoxon signed-rank test was used to estimate differences of IOP before and after surgery. The correlation between IOP and postoperative pain was evaluated by Pearson's correlation test. For binary dependent variables, we used McNemar's chi-squared test. Statistical analysis was performed using the SPSS PASW Statistics version 18.0 (IBM Corporation, Armonk, NY, USA). $P$-values less than 0.05 were considered statistically significant.

\section{Results}

\section{Patient characteristics}

A total of 110 consecutive patients were enrolled in this study. However, for four patients, the scheduled 
operation was cancelled because they gave up treatment. Ten patients were further excluded because of the concurrent cataract, and thus underwent vitrectomy combined with phacoemulsification. No complete postoperative data were available for nine patients because they gave up during the follow-up process. As a result, a total of 87 patients (41 men and 46 women) aged between 22 and 80 years (median: 60 years) were included in the final analysis. Their demographic characteristics and indications for surgery are recorded in Table 1. The number of patients who underwent $20 \mathrm{G}$ vitrectomy with the different operation modes and different types of intravitreal injections (gas, silicone oil) are shown in Table 2.

\section{Pain scores}

The median of pre- and postoperative pain scores are shown in Figure 1A. At baseline before the surgery, there were four patients (4.6\%) that reported ocular pain, and one of them had a pain score of 4 points (moderate pain). The other patients did not report any preoperative pain, with a pain score of 0 . Before surgery, the average pain score was 0.08 (SD: 0.46) before surgery.

At 1 day after surgery, 43 patients $(49.4 \%)$ reported ocular pain. The average pain score was 1.30 (SD: 1.60). Thirty-two patients had mild pain (1-3 points) and eleven patients had moderate pain (4-5 points). However, only four patients with moderate pain needed the analgesics (orally administered diclofenac sodium) to alleviate the pain, while other patients could endure the pain.

At 3 days after surgery, 39 patients (44.8\%) reported ocular pain. The average pain score was 1.03 (SD: 1.38).

Table I Demographic and indications for surgery in 87 patients who underwent 20-gauge vitrectomy

\begin{tabular}{ll}
\hline Characteristic & Number of patients (\%) \\
\hline Sex & $4 I(47)$ \\
$\quad$ Male & $46(53)$ \\
Female & 58.9 \\
Mean age (years) & \\
Concomitant diseases & $19(2 \mathrm{I} .8)$ \\
$\quad$ Diabetes mellitus & $5(5.7)$ \\
Hypertension & 109.4 \\
Mean operative time (minutes) & \\
Indication for surgery & $50(57.5)$ \\
Rhegmatogenous retinal detachment & $24(27.6)$ \\
Vitreous hemorrhage & $5(5.7)$ \\
Diabetic retinopathy & $4(4.6)$ \\
Epiretinal membranes & I (I.I) \\
Vitreous opacity & I (I.I) \\
Acute retinal necrosis & I (I.I) \\
Intraocular foreign body & I (I.I) \\
Retinal breaks &
\end{tabular}

Table 2 Number of patients who underwent vitrectomy with different operation modes and different types of intravitreal tamponade

\begin{tabular}{ll}
\hline $\begin{array}{l}\text { Operation mode and } \\
\text { intravitreal tamponade }\end{array}$ & Number of patients (\%) \\
\hline Laser & $18(20.7)$ \\
Freeze & $2(2.3)$ \\
Gas & $1(1.1)$ \\
Laser + gas & $7(8.1)$ \\
Freeze + gas & $2(2.3)$ \\
Laser + silicone oil & $33(37.9)$ \\
Freeze + silicone oil & $17(19.5)$ \\
Laser + freeze + silicone oil & $3(3.5)$ \\
None & $4(4.6)$ \\
\hline
\end{tabular}

Thirty-four patients had mild pain and five patients had moderate pain. However, only two of these 39 patients with pain had taken analgesics (orally administered diclofenac sodium) to alleviate the pain.

At 7 days after surgery, 31 of 87 patients (35.6\%) reported pain, and the average pain score was 0.62 (SD: 1.03). Thirty patients had mild pain and one patient had moderate pain. However, none of the patients with ocular pain had taken any analgesics to alleviate the pain.

At 1 month after surgery, 20 of 87 patients (23.0\%) reported mild pain, and the pain score ranged from 1 to 3 points. The average pain score was 0.30 (SD: 0.61 ). None of the patients had taken analgesics to alleviate the pain.

At 2 months after surgery, eleven of 87 patients (12.6\%) reported mild pain, and the pain score ranged from 1 to 2 points. The average pain score was 0.14 (SD: 0.38). None of the patients had taken analgesics to alleviate the pain.

\section{IOP}

The median overall preoperative IOP was $13 \mathrm{mmHg}$ (range: 5-24 mmHg). The median postoperative IOP values were $17 \mathrm{mmHg}$ (range: $10-50 \mathrm{mmHg}$ ) (compared with preoperative; $P<0.05$ ) at day $1,17 \mathrm{mmHg}$ (range: $8-50 \mathrm{mmHg})(P<0.05)$ at day $3,15 \mathrm{mmHg}$ (range: $10-49 \mathrm{mmHg})(P<0.05)$ at day 7 , $15 \mathrm{mmHg}$ (range: $10-21 \mathrm{mmHg})(P<0.05)$ at 1 month, and $14 \mathrm{mmHg}$ (range: $10-25 \mathrm{mmHg})(P<0.05)$ at 2 months. The median IOP values pre- and postoperatively are shown in Figure 1B. A postoperative rise of IOP was noted in 25 (28.7\%) patients at day 1, $18(20.7 \%)$ patients at day 3, 12 (13.8\%) patients at day 7, two (2.3\%) patients at 1 month, and two $(2.3 \%)$ patients at 2 months after surgery. Most of these patients with high IOP had moderate pain. Strong correlations were found between the IOP and the postoperative pain at day $1(r=0.427 ; P<0.05)$, day $3(r=0.493$; $P<0.05)$, day $7(r=0.288 ; P<0.05)$, and 1 month $(r=0.346$; 

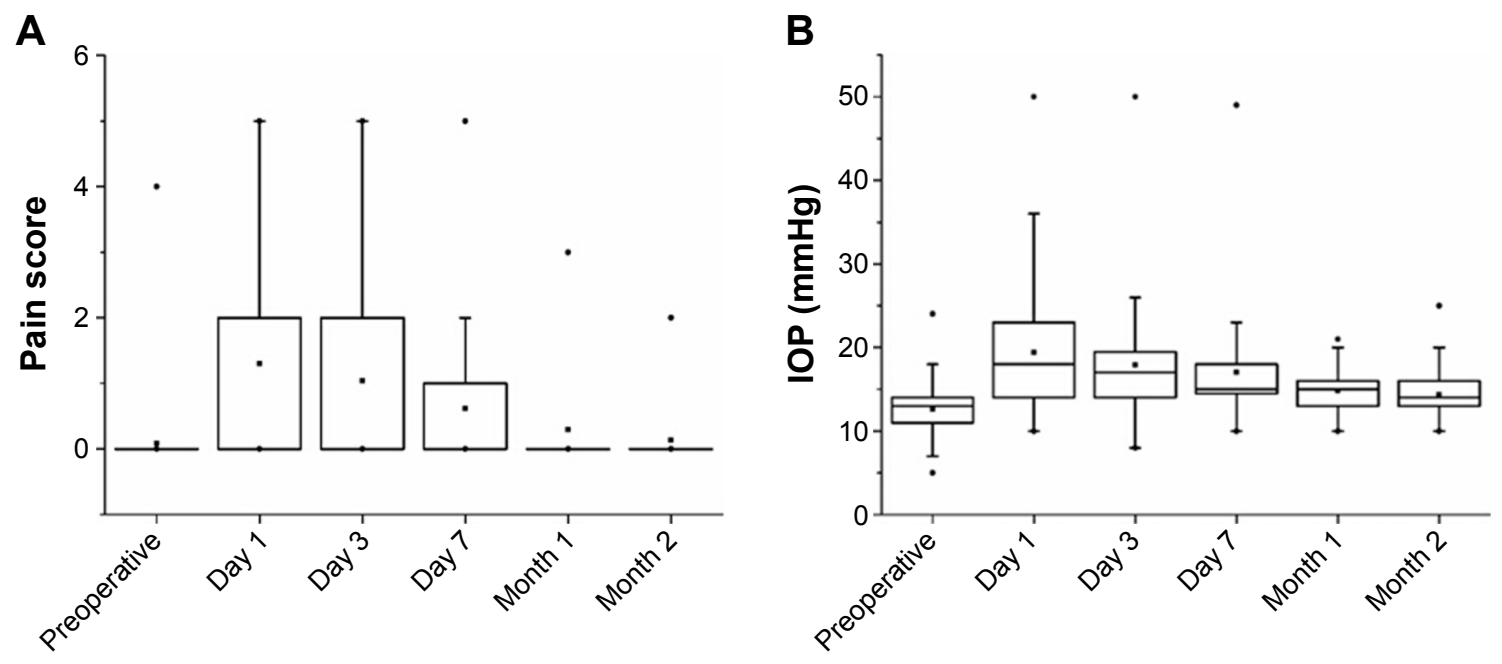

Figure I The median pain score and IOP values pre- and postoperatively.

Notes: (A) Median pain score; (B) IOP values. The dots indicate maximum value, minimum value and average value.

Abbreviation: IOP, intraocular pressure.

$P<0.05)$, but they were not found at 2 months $(r=0.022$; $P>0.05)$.

\section{Other ocular symptoms}

Before surgery, less than $11 \%$ of patients reported ocular symptoms, such as itching, foreign body sensation, burning, photophobia, and dryness (Figure 2). However, these symptoms occurred frequently after surgery, with foreign body sensation ( $49.4 \%$ at day $1,47.1 \%$ at day 3 , and $46 \%$ at day 7 ) being the most common symptom to occur within 1 week after surgery; it was then reduced significantly after 1 week $(P<0.05)$. Other symptoms like photophobia and itching maintained a prevalence rate of approximately $20 \%$ and $10 \%$,

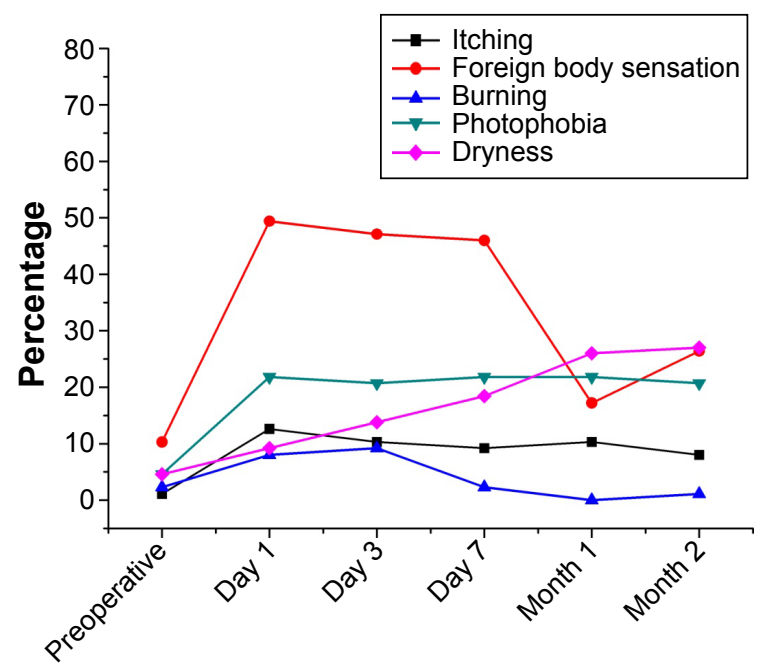

Figure 2 Variation in the number of patients with any ocular irritation symptoms before and after 20 -gauge vitrectomy. respectively, until the end of the follow-up. The number of patients that experienced a burning sensation was increased within 1 week, and it significantly declined 1 week later $(P<0.05)$. However, the prevalence of ocular dryness was gradually increased during the follow-up period after surgery (from $4.6 \%$ at day 1 to $30.1 \%$ at month 2). Nevertheless, there were still one-quarter of patients that had foreign body sensation and dryness symptoms at month 2 after surgery.

\section{Discussion}

At present, sutureless $23 \mathrm{G}$ and $25 \mathrm{G}$ pars plana vitrectomies are increasing in popularity. Compared to the $20 \mathrm{G}$ vitrectomy, sutureless $23 \mathrm{G}$ and $25 \mathrm{G}$ techniques can decrease patients' discomfort, shorten operation times, and improve postoperative astigmatism because of no conjunctival peritomy. ${ }^{4,9-11}$ However, $23 \mathrm{G}$ or $25 \mathrm{G}$ vitrectomies also have certain disadvantages. For example, instruments used for the smaller-gauge procedure are flexible, leading to difficulty with the clearance of dense vitreous hemorrhage. ${ }^{12}$ Moreover, it is difficult to inject high-viscosity silicone oil into the vitreous body with the smaller-gauge techniques. ${ }^{13}$ Furthermore, both $23 \mathrm{G}$ and $25 \mathrm{G}$ vitrectomies require completely different sets of instruments, making surgery costs higher than for $20 \mathrm{G}$ vitrectomy. ${ }^{14}$ Thus, we believe that the $20 \mathrm{G}$ vitrectomy is able to show some advantages when compared with the $23 \mathrm{G}$ and $25 \mathrm{G}$ vitrectomies, and it provides some additional benefits. It uses nonflexible and cheaper surgical instruments, and it is qualified for use in many complex vitreoretinal diseases. ${ }^{15-17}$ With the $20 \mathrm{G}$ scleral tunnel, it is possible to use high-speed cutters with high infusion/aspiration rates, 
giving the surgeon better control. It is also easy to perform injections of high-viscosity silicone oil. ${ }^{18}$ Meanwhile, 20G, $23 \mathrm{G}$, and $25 \mathrm{G}$ vitrectomies are equally effective for curing some retinal diseases, such as pseudophakic rhegmatogenous retinal detachment. ${ }^{19}$ Therefore, although the sutureless $23 \mathrm{G}$ and 25G techniques developed well, it is still appropriate and preferable to choose $20 \mathrm{G}$ vitrectomy systems for treating some vitreoretinal diseases, especially in the People's Republic of China, which has a large population and is an economically underdeveloped country.

This was one of the follow-up studies featuring postoperative discomfort as a primary outcome measure among Chinese people after 20G pars plana vitrectomy. Our data showed that pain and other ocular symptoms were relatively common after $20 \mathrm{G}$ pars plana vitrectomy. However, postoperative pain and ocular irritation symptoms varied between individuals and varied in duration. In this study, approximately half of the patients reported mild and moderate pain and serious foreign body sensation within 1 week, and these symptoms were then reduced during the follow-up process. At the end of the follow-up, there was still onequarter of patients that reported foreign body sensation and dryness symptoms, although most of the patients recovered with no discomfort. Other symptoms, such as pain, itching, burning, and photophobia, also existed in some patients at 2 months. In view of this, to prevent and alleviate postoperative discomfort, patients with continuous postoperative pain or other ocular symptoms must be identified, and appropriate counseling and drug treatment should be provided.

To the best of our knowledge, many factors can make patients experience postoperative ocular pain, including corneal epithelial defects, extensive conjunctival dissection, muscle isolation, release of adhesions at reoperation, placement of large buckling elements, and choroidal effusions. ${ }^{20}$ That should also include the scleral wound and postoperative uveitis. Nevertheless, IOP often increases significantly on the first day after $20 \mathrm{G}$ vitrectomy, and the elevated IOP will also lead to ocular pain. ${ }^{21}$ In this study, we found that high IOP was commonly encountered within 1 week after surgery, and that most patients reported moderate pain with an IOP greater than $30 \mathrm{mmHg}$. This means that the postoperative ocular pain was not only related to the conjunctival-scleral incisions and postoperative uveitis, but also with the occurrence of high IOP. Moreover, the serious foreign body sensation may be related to the sutures of the conjunctival incisions ${ }^{22}$ that cause an inflammatory process around the sutures. ${ }^{5}$ With the absorption of the sutures, the foreign body sensation was gradually alleviated.
A previous study reported that the postoperative ocular irritation symptoms may be associated with systemic diseases, such as diabetes mellitus, hypertension, rheumatoid disease, thyroid dysfunction, cancer, and so on. ${ }^{23}$ At the same time, ocular symptoms perhaps also occur in association with advanced age, which may affect symptom perception and expression. Elderly individuals often have different severity levels of dry eye syndrome and various other ocular symptoms. ${ }^{24}$ However, in the present study, the patients were relatively young (median: 60 years; range: $22-80$ years) and the prevalence of patients with systemic diseases such as diabetes mellitus (21.8\%) and hypertension (5.7\%) was not high. As such, we hold the opinion that, to some extent, the ocular symptoms were related to surgery. The $20 \mathrm{G}$ vitrectomy, which requires three large incisions on the conjunctiva and sclera, features a long operation time; it also damages the microenvironment of the ocular surface, resulting in a number of the different ocular symptoms that occurred.

In the present study, only four patients were given analgesics to alleviate ocular pain during the first postoperative week. The number of patients were significantly lower than that reported in the data of a previous retrospective study. ${ }^{6}$ In that study, there were 64 patients taking pain medications during the first postoperative week. ${ }^{6}$ This difference may be related to the point that Chinese people regard postoperative pain is a normal process after surgery, and that there is no need for oral analgesic drugs to alleviate mild and moderate pain.

The study has some limitations with respect to both the experimental design and the outcome measures. First, the sample size was too small to confirm whether analgesics must be used. Second, the duration was limited to 2 months, meaning that we were unable to determine whether these irritation symptoms would disappear 2 months later. Furthermore, we only chose five common ocular symptoms for observation, while any other irritation symptoms were not investigated, such as lacrimation, sense of acupuncture, and so on. In addition, we were unable to explore the dry eye symptoms adopting the methods of tear break-up time, corneal fluorescein staining, the Schirmer I test, and corneal sensitivity.

\section{Conclusion}

In conclusion, at least half of the patients have mild and moderate ocular pain after 20G vitrectomy, which may last up to 2 months in some patients. Other ocular irritation symptoms were also present, and they varied based on the longer duration of follow-up. Thus, the discomforts after $20 \mathrm{G}$ pars plana vitrectomy must be of concern, and their 
timely management should be provided as part of routine postoperative care. Drugs such as analgesics, nonsteroidal anti-inflammatory drugs, and artificial tears may be helpful in alleviating the ocular pain and irritation symptoms after $20 \mathrm{G}$ vitrectomy.

\section{Disclosure}

The authors report no conflicts of interest in this work.

\section{References}

1. Schwartz SG, Flynn HW Jr, Mieler WF. Update on retinal detachment surgery. Curr Opin Ophthalmol. 2013;24(3):255-261.

2. Gupta V, Arevalo JF. Surgical management of diabetic retinopathy. Middle East Afr J Ophthalmol. 2013;20(4):283-292.

3. Spirn MJ. Comparison of 25, 23 and 20-gauge vitrectomy. Curr Opin Ophthalmol. 2009;20(3):195-199.

4. Spierer O, Siminovsky Z, Loewenstein A, Barak A. Outcomes of 20-gauge transconjunctival sutureless vitrectomy. Retina. 2011;31(9): $1765-1771$.

5. Mentens R, Devogelaere T, Stalmans P. Comparing fibrin glue to sutures for conjunctival closure in pars plana vitrectomy. Bull Soc Belge Ophtalmol. 2007;(306):49-56.

6. Mentens R, Stalmans P. Comparison of postoperative comfort in 20 gauge versus 23 gauge pars plana vitrectomy. Bull Soc Belge Ophtalmol. 2009;(311):5-10.

7. Ruskin $\mathrm{D}$, Lalloo C, Amaria K, et al. Assessing pain intensity in children with chronic pain: convergent and discriminant validity of the 0 to 10 numerical rating scale in clinical practice. Pain Res Manag. 2014;19(3): 141-148.

8. Ferreira-Valente MA, Pais-Ribeiro JL, Jensen MP. Validity of four pain intensity rating scales. Pain. 2011;152(10):2399-2404.

9. Tsang CW, Cheung BT, Lam RF, et al. Primary 23-gauge transconjunctival sutureless vitrectomy for rhegmatogenous retinal detachment. Retina. 2008;28(8):1075-1081.

10. Yanyali A, Celik G, Dincyildiz A, Horozoglu F, Nohutcu AF. Primary 23-gauge vitreoretinal surgery for rhegmatogenous retinal detachment. Int J Ophthalmol. 2012;5(2):226-230.
11. Galway G, Drury B, Cronin BG, Bourke RD. A comparison of induced astigmatism in 20- vs 25-gauge vitrectomy procedures. Eye (Lond). 2010;24(2):315-317.

12. O' Reilly P, Beatty S. Transconjunctival sutureless vitrectomy: initial experience and surgical tips. Eye (Lond). 2007;21(4):518-521.

13. Oliveira LB, Reis PA. Silicone oil tamponade in 23-gauge transconjunctival sutureless vitrectomy. Retina. 2007;27(8):1054-1058.

14. Lewis H. Sutureless microincision vitrectomy surgery: unclear benefit, uncertain safety. Am J Ophthalmol. 2007;144(4):613-615.

15. Sheng Y, Sun W, Mo B, Yu YJ, Gu YS, Liu W. Non-buckled vitrectomy for retinal detachment with inferior breaks and proliferative vitreoretinophathy. Int J Ophthalmol. 2012;5(5):591-595.

16. Qamar RM, Saleem MI, Saleem MF. The outcomes of pars plana vitrectomy without endotamponade for tractional retinal detachment secondary to proliferative diabetic retinopathy. Int J Ophthalmol. 2013; 6(5):671-674.

17. Zhang J, Zhu XH, Tang LS. Rhegmatogenous retinal detachment associated with massive spontaneous suprachoroidal hemorrhage and prognosis of pars plana vitrectomy. Int J Ophthalmol. 2014;7(5):850-854.

18. Lafetá AP, Claes C. Twenty-gauge transconjunctival sutureless vitrectomy trocar system. Retina. 2007;27(8):1136-1141.

19. Lewis SA, Miller DM, Riemann CD, Foster RE, Petersen MR. Comparison of 20-, 23-, and 25-gauge pars plana vitrectomy in pseudophakic rhegmatogenous retinal detachment repair. Ophthalmic Surg Lasers Imaging. 2011;42(2):107-113.

20. Er H. Intraoperative ketorolac and eye pain after vitreoretinal surgery: a prospective, randomized, placebo-controlled study. Retina. 2004;24(1): 182-183; author reply 183 .

21. Sandali O, El Sanharawi M, Lecuen N, et al. 25-, 23-, and 20-gauge vitrectomy in epiretinal membrane surgery: a comparative study of 553 cases. Graefes Arch Clin Exp Ophthalmol. 2011;249(12):1811-1819.

22. Rizzo S, Genovesi-Ebert F, Murri S, et al. 25-gauge, sutureless vitrectomy and standard 20-gauge pars plana vitrectomy in idiopathic epiretinal membrane surgery: a comparative pilot study. Graefes Arch Clin Exp Ophthalmol. 2006;244(4):472-479.

23. Porela-Tiihonen S, Kaarniranta K, Kokki M, Purhonen S, Kokki H. A prospective study on postoperative pain after cataract surgery. Clin Ophthalmol. 2013;7:1429-1435.

24. Erb C, Gast U, Schremmer D. German register for glaucoma patients with dry eye. I. Basic outcome with respect to dry eye. Graefes Arch Clin Exp Ophthalmol. 2008;246(11):1593-1601.
Clinical Ophthalmology

\section{Publish your work in this journal}

Clinical Ophthalmology is an international, peer-reviewed journal covering all subspecialties within ophthalmology. Key topics include: Optometry; Visual science; Pharmacology and drug therapy in eye diseases; Basic Sciences; Primary and Secondary eye care; Patient Safety and Quality of Care Improvements. This journal is indexed on Submit your manuscript here: http://www.dovepress.com/clinical-ophthalmology-journal

\section{Dovepress}

PubMed Central and CAS, and is the official journal of The Society of Clinical Ophthalmology (SCO). The manuscript management system is completely online and includes a very quick and fair peer-review system, which is all easy to use. Visit http://www.dovepress.com/ testimonials.php to read real quotes from published authors. 